The Egyptian Journal of Hospital Medicine (October 2019) Vol. 77 (3), Page 5109-5113

\title{
Pregnancy Outcome in Women with Previous One Cesarean Section, Experience from Kingdom of Saudi Arabia
}

\author{
Fatimah Alkhamis \\ Department of Obstetrics and Gynecology, Faculty of Medicine, King Faisal University, Saudi Arabia \\ Corresponding Author: Fatimah Alkhamis, Drfatimah7070@ hotmail.com \\ Maternity and Children Hospital Al-HASA, Kingdom of Saudi Arabia
}

\begin{abstract}
Objectives: The aim of this study is to determine the outcome of pregnancy in women with previous one cesarean section as successful trial of scar and vaginal delivery, and repeated caesarian section.

Methodology: This is a retrospective cohort hospital-based study was conducted in Maternity and Children Hospital AlHASA. Included booked women and non-booked pregnant women and had previous one cesarean section. Data were collected from delivery room log book and medical files when more details were required. Those who were eligible for the study were 299 women who underwent comprehensive analysis.

Main results: The successful vaginal delivery was (73.9\%). No reported cases of maternal mortality or morbidity. However, there were tender scar with no dehiscence or rupture uterus $(4 \%)$. No neonatal mortality, however, $6 \%$ of the CS were indicated by fetal distress. There was statistically significant association between gestational age and fetal weight $(\mathrm{P}<0.01)$ and between the gestational age and Apgar score $(\mathrm{P}<0.01)$. Significant results was found between outcome and previous successful vaginal birth after cesarean $(\mathrm{VBAC})(\mathrm{P}<0.001)$ and with spontaneous vaginal deliveries $(\mathrm{P}$ Value $0.004)$ and between previous cause of $\mathrm{C}$-Section and the outcome was highly significant $(\mathrm{P}<0.001)$.

Conclusion: In this study the maternal and fetal outcome of VBAC were quite satisfactory. Policy maker can use the findings of this study to develop strategy to decrease the cesarean section rate. Safe practice that enhances VBAC success rate without increasing mortality and morbidity should be evaluated.
\end{abstract}

Keywords: VBAC, maternal, fetal, outcome, Saudi Arabia.

\section{INTRODUCTION}

World Health Organization (WHO) recommended the expected rate of cesarean to be as low as $15 \%$ however, it's documented as $13 \%{ }^{(1)}$. The probability that a woman undergoes a cesarean is 3 times more than that of 20 years ago ${ }^{(2)}$. There were increased in caesarean section (C-section) rate with different variation in countries ${ }^{(3)}$. The caesarean rate in Brazil, Chile and China increased up to $40-42 \%(4,5)$, in Iran 26- $66.5 \%$ and it's as high as $87 \%$ in private centers ${ }^{(6,7)}$. Cesarean delivery is carried out due to such various reasons as pregnancy at higher ages, lower number of a woman previous pregnancies, obesity, fetal distress, etc. ${ }^{(8,9)}$. The single best predictor for successful VBAC is previous vaginal birth, particularly previous VBAC which is associated with an approximately $87-90 \%$ planned VBAC success rate ${ }^{(10,11)}$.

In Kingdom of Saudi Arabia (KSA) there was increase in the overall cesarean delivery rate by $80.2 \%$ from $10.6 \%$ in 1997 to $19.1 \%$ in 2006 in different regions ${ }^{(12)}$. Recent study showed a high rate of cesarean delivery $(55.4 \%$.), and obese women were at higher risk to deliver by cesarean ${ }^{(13)}$. A number of factors are associated with successful VBAC. Risk factors for unsuccessful VBAC are: induced labour, no previous vaginal birth, high body mass index and previous caesarean section for dystocia. When all these factors are present, successful VBAC is achieved in only $40 \%$ of cases. There are numerous other factors associated with a decreased likelihood of planned VBAC success: VBAC at or after 41 weeks of gestation, birth weight greater than $4000 \mathrm{~g}$; no epidural anaesthesia, previous preterm caesarean birth, cervical dilatation at admission less than $4 \mathrm{~cm}$, less than 2 years from previous caesarean birth, advanced maternal age, non-white ethnicity, short stature and a male infant ${ }^{(14)}$.

Women with previous cesarean sections constitute a high risk group in obstetrics. Vaginal birth after cesarean (VBAC) or trial of scar (TOS)represents a significant change in modern obstetric practice. However, the concern that a scarred uterus might end up in rupturing the uterus, leading to severe maternal and perinatal morbidity that still prevents a large number of obstetricians and pregnant women worldwide from adopting a TOS after previous one cesarean section ${ }^{(15)}$.

In Saudi Arabia, where having a big family is the social normal, VBAC after a prior cesarean is important issue with special consideration in Saudi population. The aim of this study is to determine the outcome of pregnancy in women with previous one cesarean section as successful trial of scar and vaginal delivery, and repeated caesarian section.

\section{METHODOLOGY}

This is a retrospective cohort hospital based study, which was carried out in a tertiary care hospital that serves a steady population of the civilians and their dependents, the Maternity and Children Hospital AlHASA. This hospital offer elective service as well as 
emergency service all over the day. Also it is well recognized training center for both undergraduates and postgraduates students.

The population of this study were booked women and non-booked that came in labor. Women delivered in the period from $1 / 6 / 1437$ to $30 / 12 / 1437$ (11/3/2016 to 3/10/2016 were considered.

All patients that came in labor with history of one previous $\mathrm{C} / \mathrm{S}$ and above or equal to 36 weeks gestational age. Any patient with gestational age less than 36 weeks, IUFD, congenital anomaly and with placenta previa were excluded.

Data were collected from delivery room log book and medical files when more details were required. Those who were eligible for the study were 299 women who underwent comprehensive analysis. The total number of delivery during the study period was used to calculate the incidence of successful VBAC.

Data were analyzed by SPSS for windows version 25 (SPSS Inc, Chicago, IL). Summary data were expressed as means \pm standard deviation (SD) for continuous variables. Chi-Square Tests used to study the relation between cause of previous CS and outcome, between the cause of previous C/S and repeated CS, between the gestational age and outcome, between previous NSVD and outcome, and previous successful VBAC and outcome. Comparison of baseline and post operation parameters as baby weight and APGAR score was performed using paired $\mathrm{t}$ test. A $\mathrm{P}<0.05$ was considered statistically significant.

\section{ETHICAL CLEARANCE}

Our concern was patient confidentiality and medical information, this confidentiality would be secured by using only the number and not the patient name in our data collection sheet, and on top all data was protected by password. Ethical clearance was obtained from hospital review board.

\section{RESULT}

In this retrospective cohort study 299 Women were enrolled. Mean age \pm SD was $30.12 \pm 5.9(\min 18-\max$ $42)$. The gravidity mean was $4.01 \pm 1.18(\min 2-\max 12)$. Parity mean was $2.5 \pm 2.9$ (min 18- $\max 6)$. Abortion mean was $0.5 \pm 0.9$ ( $\min 0-\max 7)$. Gestational age mean was $38.9 \pm 5.9(\min 36-\max 42)$. Mean of previous VBAC was $1.7 \pm 1.1(\min 1-\max 6)$ and mean of NSVD was $2.3 \pm 1.5(\min 1-\max 7)$. The gestation age was 40 weeks or more in 144/299 (48.2\%) women, 37-39 weeks were $140 / 299(46.8 \%)$ and few were 36 weeks represented 15/299 (5\%). The association of gestational age and outcome of VBAC was not significant statistically ( $\mathrm{P}$ value 0.42 ).

The common indications for the previous $\mathrm{C}$ section are shown in table 1.

Table 1: Distribution according to the indication of previous $C$ section. Pregnancy outcome in women with previous one cesarean section in MCH-ALHASA, Saudi Arabia.

\begin{tabular}{|c|c|c|c|}
\hline indication of previous C Section & Frequency & Percent & $\mathrm{P}$ value \\
\hline Fetal distress & 117 & 39.1 & \multirow[t]{17}{*}{0.8} \\
\hline Failure to progress & 58 & 19.4 & \\
\hline Breech presentation & 44 & 14.7 & \\
\hline Hypertensive disorder & 19 & 6.4 & \\
\hline Transverse lie & 14 & 4.7 & \\
\hline Antepartum hemorrhage (APH) & 12 & 4 & \\
\hline Big baby & 7 & 2.3 & \\
\hline Multiple pregnancy & 5 & 1.7 & \\
\hline Failed induction & 4 & 1.3 & \\
\hline Face presentation & 2 & 0.7 & \\
\hline Postdate, prom, failed induction & 2 & 0.7 & \\
\hline Bicornuate uterus & 1 & 0.3 & \\
\hline Congenital anomaly & 1 & 0.3 & \\
\hline Gestational diabetes mellitus (GDM) & 1 & 0.3 & \\
\hline IUGR & 1 & 0.3 & \\
\hline Oblique lie & 1 & 0.3 & \\
\hline Fetal distress & 1 & 0.3 & \\
\hline Total & 299 & 100 & \\
\hline
\end{tabular}

The successful vaginal delivery was 221/299 (73.9\%) including 3 vacuum delivery. The failure of VBAC was accounted 78/299 (26.1\%). There was significant association between the cause of previous C/S and repeated CS (P value 0.001) (Table 2). 
Table 2: Distribution according to the outcome of delivery. Pregnancy Outcome in Women with Previous One Cesarean Section in MCH-ALHASA, Saudi Arabia.

\begin{tabular}{|l|c|c|c|}
\hline Mode of delivery & Frequency & Percent & \multirow{2}{*}{ P value } \\
\hline Cesarean section & 78 & 26.1 & \multirow{2}{*}{$<0.001$} \\
\cline { 1 - 2 } NSVD & 218 & 72.9 & \\
\cline { 1 - 3 } Vacuum & 3 & 1.0 & \\
\cline { 1 - 2 } Total & $\mathbf{2 9 9}$ & $\mathbf{1 0 0}$ & \\
\hline
\end{tabular}

The two common causes of repeated CS were failure to progress 38/299 (12.7\%) and fetal distress 18/299 (6\%). There was no statistically significant association (P value 0.46 ) between successful VBAC and cause previous CS (Table 3).

Table 3: Distribution according to the causes of repeated CS and association with successful VBAC. Pregnancy outcome in women with previous one cesarean section in MCH-ALHASA, Saudi Arabia. (N=79/299)

\begin{tabular}{|c|c|c|c|}
\hline Causes of repeated CS & Frequency & Percent & $P$ value \\
\hline Failure to progress & 38 & 12.7 & \multirow[t]{11}{*}{0.46} \\
\hline Fetal distress & 18 & 6 & \\
\hline Tender scar (no dehiscence) & 7 & 2.3 & \\
\hline Scar tenderness, (no rupture uterus) & 5 & 1.7 & \\
\hline $\mathrm{APH}$ & 3 & 1 & \\
\hline Big baby & 2 & 0.7 & \\
\hline Compound presentation & 2 & 0.7 & \\
\hline Hyperstimulation, CPD & 1 & 0.3 & \\
\hline PET & 1 & 0.3 & \\
\hline PROM more than 48 & 1 & 0.3 & \\
\hline Bicornuate uterus & 1 & 0.3 & \\
\hline Total & 79/299 & 26.3 & \\
\hline
\end{tabular}

Chi-Square Tests

\begin{tabular}{|c|c|c|c|}
\hline & Value & df & Asymptotic Significance (2- sided) \\
\hline Pearson Chi-Square & $3.856^{\mathrm{a}}$ & 4 & .426 \\
\hline Likelihood Ratio & 4.992 & 4 & .288 \\
\hline $\mathrm{N}$ of Valid Cases & 299 & & \\
\hline
\end{tabular}

There were statistically significant association between gestational age and baby weight ( $\mathrm{P}$ value 0.00$)$ and between the gestational age and Apgar score (P value 0.00). The correlation between previous cause of $\mathrm{C}$-Section and the repeated CS outcome is highly significant $(\mathrm{P}<0.001)$ (Table 4$)$.

Table 4: Distribution according to the gestational age. Pregnancy Outcome in Women with Previous One Cesarean Section in MCH-ALHASA, Saudi Arabia. (N=299)

\begin{tabular}{|l|c|c|c|c|}
\hline Gestational age & Frequency & Percent & Valid \% & Cumulative \% \\
\hline 36 weeks & 15 & 5.0 & 5.0 & 5.0 \\
\hline 37-39 weeks & 140 & 46.8 & 46.8 & 51.8 \\
\hline 40 week and more & 144 & 48.2 & 48.2 & 100.0 \\
\hline Total & $\mathbf{2 9 9}$ & $\mathbf{1 0 0 . 0}$ & $\mathbf{1 0 0 . 0}$ & \\
\hline
\end{tabular}

Paired Samples Statistics

\begin{tabular}{|l|l|r|r|r|r|}
\hline \multicolumn{2}{|c}{} & Mean & N & . Deviation & l. Error Mean \\
\hline Pair 1 & GA & 38.92 & 298 & 2.645 & .153 \\
\cline { 2 - 6 } & BABY WT & 3210.00 & 298 & 425.519 & 24.650 \\
\hline \multirow{2}{*}{ Pair 2 } & GA & 38.92 & 298 & 2.645 & .153 \\
\cline { 2 - 6 } & Apgar5 & 7.9664 & 298 & .48431 & .02806 \\
\hline
\end{tabular}


ejhm.journals.ekb.eg

\begin{tabular}{|c|c|c|c|c|c|c|c|c|}
\hline \multicolumn{9}{|c|}{ Paired Samples Test } \\
\hline & \multicolumn{5}{|c|}{ Paired Differences } & \multirow{3}{*}{$\mathrm{t}$} & \multirow{3}{*}{ df } & \multirow{3}{*}{$\begin{array}{l}\text { Sig. } \\
(2- \\
\text { tailed })\end{array}$} \\
\hline & \multirow{2}{*}{ Mean } & \multirow{2}{*}{$\begin{array}{c}\text { Std. } \\
\text { Deviation }\end{array}$} & \multirow{2}{*}{$\begin{array}{r}\text { Std. } \\
\text { Error } \\
\text { Mean }\end{array}$} & \multicolumn{2}{|c|}{$\begin{array}{l}\text { 95\% Confidence } \\
\text { Interval of the } \\
\text { Difference }\end{array}$} & & & \\
\hline & & & & Lower & Upper & & & \\
\hline \begin{tabular}{l|l} 
Pair 1 & GA - BABY WT \\
\end{tabular} & $-3171.081-$ & 425.234 & 24.633 & $-3219.558-$ & $-3122.603-$ & $-128.732-$ & 297 & .001 \\
\hline Pair 2 GA - Apgar5 & 30.95638 & 2.70081 & .15645 & 30.64848 & 31.26427 & 197.863 & 297 & .001 \\
\hline
\end{tabular}

Those with previous spontaneous vaginal delivery were 139/299 (46.5\%) and those Previous successful VBAC were 64/299 (21.3\%). These two factor will affect the chance of successful VBAC at present. The relationship between NSVD and outcome was statistically significant (P Value 0.004) while it's also significant with those had previous successful VBAC (P Value 0.001). The correlation between previous cause of $\mathrm{C}$-Section and the outcome is highly significant ( $\mathrm{p}$ value 0.000$)$.(table 5)

Table 5: Distribution according to previous NSVD, previous VBAC and the relationship with the outcome. Pregnancy outcome in women with previous one cesarean section in MCH-ALHASA, Saudi Arabia (N=299)

\begin{tabular}{|l|c|c|c|c|}
\hline \multicolumn{2}{|c|}{ Parameters } & Frequency & Percent & \multirow{2}{*}{ P value } \\
\hline \multirow{3}{*}{$\begin{array}{l}\text { Previous } \\
\text { NSVD }\end{array}$} & Yes & 139 & 46.5 & \multirow{3}{*}{0.004} \\
\cline { 2 - 4 } & No & 160 & 53.5 & \\
\cline { 2 - 4 } $\begin{array}{l}\text { Previous } \\
\text { successful VBAC }\end{array}$ & Total & 299 & 100 & \multirow{2}{*}{$<0.001$} \\
\cline { 2 - 4 } & yes & 64 & 21.3 & \\
\cline { 2 - 4 } & Total & 235 & 78.1 & \\
\hline
\end{tabular}

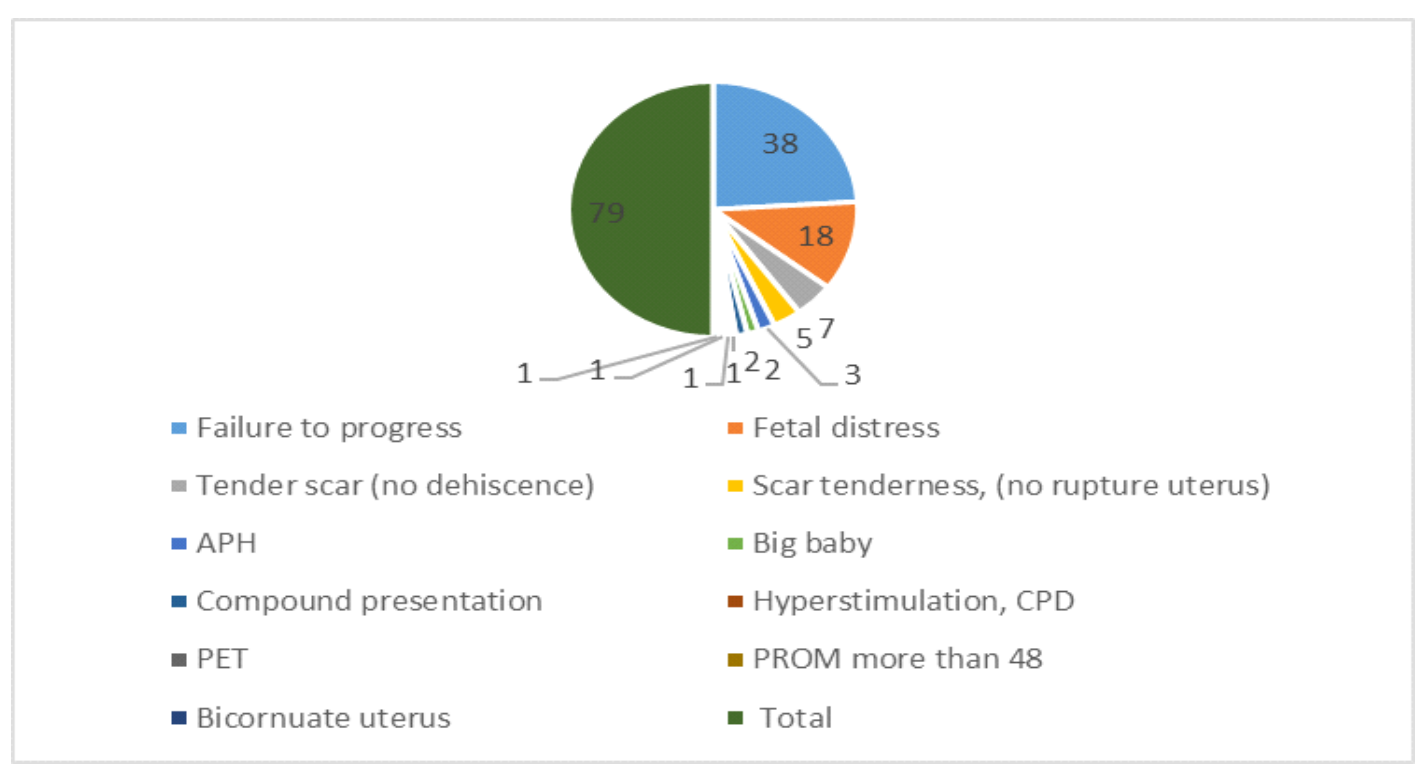

Figure 1: Distribution according to the cuses of repeated CS and association with successful VBAC. Pregnancy outcome in women with previous one cesarean section in MCH-ALHASA, Saudi Arabia. (N=79/299)

\section{DISCUSSION}

This study provided valuable data regarding one of the major concerns, which is rising rate of cesarean section deliveries in Saudi Arabia. This study indicated that the successful vaginal delivery was $(73.9 \%)$. Significant association was found between the cause of previous $\mathrm{C} / \mathrm{S}$ and repeated CS $(\mathrm{P}<0.001)$. This successful rate was comparable with other areas. It's like that in USA where successful rate ranged between $60-80 \%{ }^{(16)}$ It is better than in Australia which accounted $81 \%{ }^{(15)}$. The high VBAC rate of success in this study was achieved due to support of the skillful staff working in Maternity and Children Hospital Al-HASA and adopting of the excellent protocol management. This findings can be used as strategies to control the rising rate of cesarean sections.

In this study, the maternal outcome regarding morbidities and mortality was quite satisfactory. The satisfactory outcome included no rupture uterus, maternal 
mortality or severe obstetrics morbidities. It's comparable with that of United Kingdom where it was $0.7 \%{ }^{(17)}$. This satisfactory results represents a significant change in modern obstetric practice in Maternity and Children Hospital Al-HASA as well as in most areas in Saudi Arabia. This is possibly due to attached to the management protocol with modern update.

This study indicated satisfactory statistically significant results between gestational age and baby weight $(\mathrm{P}<0.01)$ and between the gestational age and Apgar score $(\mathrm{P}<0.01)$. This findings is comparable with the literature, which indicated that neonatal morbidity did not increase with increasing VBAC number ${ }^{(17)}$. However, previous data suggested a trend toward a greater risk of fetal death among women who undergo a trial of labor, these findings are consistent with those of McMahon and colleagues ${ }^{(18)}$, who also reported no increase in perinatal deaths at term among women undergoing a trial of labor ${ }^{(19)}$. The satisfactory fetal outcome is largely due to advanced nursey unit equipment with well-trained medical staff. Also patient's selection for VBAC played a vital roles in the outcome especially gestational age and free medical problems. as a lot of studies showed the maternal and neonatal risk of Caesarean section (CS) and they recommend ways to reducing maternal and neonatal risk by reducing rate of cesserian section $^{(20,21,22)}$.

Policy maker can use the findings of this study to develop effective strategy to decrease the cesarean section rate. Safe practice that enhance VBAC success rate without increasing mortality and morbidity should be evaluated.

Acknowledgement: I would like to thank my colleagues in Maternity and Children Hospital Al-HASA, Kingdom of Saudi Arabia. With love I thank my family for their encouragement and love.

Conflict of interest: Authors declared that no conflict of interest

Study limitation: The study confined to one center inspite of adequate study sample.

Author's contributions: Dr. Fatimah Alkhamis as the first author, she was responsible for research idea, study design, data collection and scientific writing. Nihad Alkishi was responsible for scientific writing, manuscript preparation and data interpretation.

\section{REFERENCES}

1. Bagheri A, Masoodi-Alavi N, Abbaszade F (2012): Effective factors for choosing the delivery method among the pregnant women in Kashan. Feyz J., 16:146-153.

2. Shakeri M, Mazloumzade S, Mohamaian F (2012): Factors affecting the rate of cesarean section in Zanjan maternity hospitals in 2008. Zanjan Univ Med Sci J., 20:98-104.

3. Lee AS, Kirkman M. Disciplinary discourse (2008): rates of cesarean section explained by medicine, midwifery, and feminism. Health Care Women Int., 29:448-467.
4. Betrán AP, Merialdi M, Lauer JA, Bing- Shun W, Thomas J, Van Look P et al. (2007): Rates of caesarean section: analysis of global. regional and national estimates. Paediatr Perinat Epidemiol., 21:98-113.

5. D'Orsi E, Chor D, Giffin K, Angulo-Tuesta A, Barbosa GP, Gama Ade $S$ et al. (2006): Factors associated with cesarean sections in a public hospital in Rio de Janeiro, Brazil. Cad Saúde Pública, 22:2067-2078.

6. Shariat M, Majlesi F, Azari S, Mahmoudi M (2002): Cesarean section in maternity hospitals in Tehran. Payesh., 1:5-10

7. Mohammad Pour Asl A, Rostami F, Torabi SS (2006): Prevalence of cesarean section and Its demographic correlates in Tabriz. Med J Tabriz Univ Med Sci Health Serv., 28:101-106.

8. Jamshidi Evanaki F, Khakbazan Z, Babaei G, Seyed Noori T (2004): Reasons of choosing Cesarean section as the delivery method by the pregnant women referred to healthtreatment centers in Rasht. J Hayat., 10:50-60.

9. Cunningham F, Leveno K, Bloom S, Spong CY, Dashe J (2014): Williams Obstetrics. 23e. Mcgraw-hill. https://www.worldcat.org > title > williams-obstetrics

10. Landon MB, Leindecker S, Spong CY, Hauth JC, Bloom S, Varner MW et al. (2005): The MFMU Cesarean Registry: factors affecting the success of trial of labor after previous cesarean delivery. Am JObstet Gynecol., 193:1016-1023.

11. Gyamfi C, Juhasz G, Gyamfi P, Stone JL (2004): Increased success of trial of labor after previous vaginal birth after cesarean. Obstet Gynecol., 104:715-19.

12. Ba'aqeel HS (2009): Cesarean delivery rates in Saudi Arabia:a ten-year review. Ann Saudi Med., 29(3):179-83.

13. AlSheeha MA (2018): Epidemiology of Cesarean Delivery in Qassim, Saudi Arabia. Open Access Maced J Med Sci., 6(5): 891895.

14. Selo-Ojeme $\mathrm{D}$, Abulhassan $\mathrm{N}$, Mandal $\mathrm{R}$ et al. (2008): Preferred and actual delivery mode after a cesareain London, UK. Int J GynaecolObstet., 102:156.

15. Kabir AA, Pridjian G, Steinmann WC et al. (2005): Racial differences in cesareans: an analysis of U.S. 2001 National Inpatient Sample Data. Obstet Gynecol., 105:710.

16. Selo-Ojeme $D$, Abulhassan $N$, Mandal $R$ et al. (1955): Preferred and actual delivery mode after a cesareain London, UK. Int J GynaecolObstet., 102(2):156-9.

17. Stamilio DM, Shanks (2008): A Vaginal birth after cesarean (VBAC) outcomes associated with increasing number of prior VBACs. Women's Health (LondEngl), 4(3):233-6.

18. McMahon MJ et al. (1996): Comparison of a trial of labor with an elective second cesarean section."New England journal of medicine, 335(10) 689-695.

19. Guise JM et al. (2003): Vaginal birth after cesarean (VBAC). Evidence report/technology assessment, 71:1-188.

20. Almeida MA, Araujo Júnior $\mathbf{E}$, Camano $\mathbf{L}$, Peixoto AB, Martins WP, Mattar R (2018): Impact of cesarean section in a private health service in Brazil: indications and neonatal morbidity and mortality rates. Ceska Gynekol.winter, 83(1):4-10.

21. Colmorn LB, Krebs L, Klungsøyr K, Jakobsson M, Tapper AM, Gissler M, Lindqvist PG, Källen K, Gottvall K, Bordahl PE, Bjarnadóttir RI, Langhoff-Roos J (2017): Mode of first delivery and severe maternal complications in the subsequent pregnancy. Acta Obstet Gynecol Scand., 96(9):1053-1062.

22. Mendis R, Flatley C, Kumar S (2018): Maternal demographic factors associated with emergency caesarean section for nonreassuring foetal status. J Perinat Med., 46(6):641-647. 